\title{
Preactivation of Notch1 in remote ischemic preconditioning reduces cerebral ischemia- reperfusion injury through crosstalk with the NF-kB pathway
}

Weidong Liang ${ }^{1,2}$, Chunshui Lin ${ }^{1 *}$, Liuqing Yuan², Li Chen², Peipei Guo ${ }^{1}$, Ping Li ${ }^{3}$, Wei Wang ${ }^{1}$ and Xin Zhang ${ }^{1}$

\begin{abstract}
Background: Remote ischemic preconditioning (RIPC) initiates endogenous protective pathways in the brain from a distance and represents a new, promising paradigm in neuroprotection against cerebral ischemia-reperfusion (I/R) injury. However, the underlying mechanism of RIPC-mediated cerebral ischemia tolerance is complicated and not well understood. We reported previously that preactivation of Notch1 mediated the neuroprotective effects of cerebral ischemic preconditioning in rats subjected to cerebral I/R injury. The present study seeks to further explore the role of crosstalk between the Notch1 and NF-KB signaling pathways in the process of RIPC-induced neuroprotection.
\end{abstract}

Methods: Middle cerebral artery occlusion and reperfusion (MCAO/R) in adult male rats and oxygen-glucose deprivation and reoxygenation (OGD/R) in primary hippocampal neurons were used as models of I/R injury in vivo and in vitro, respectively. RIPC was induced by a 3-day procedure with 4 cycles of 5 min of left hind limb ischemia followed by 5 min of reperfusion each day before MCAO/R. Intracerebroventricular DAPT injection and sh-Notch1 lentivirus interference were used to inhibit the Notch1 signaling pathway in vivo and in vitro, respectively. After 24 $\mathrm{h}$ of reperfusion, neurological deficit scores, infarct volume, neuronal apoptosis, and cell viability were assessed. The protein expression levels of NICD, Hes1, Phospho-IKKa/ $\beta$ (p-IKK a/ $\beta$ ), Phospho-NF-kB p65 (p-NF-kB p65), Bcl-2, and Bax were assessed by Western blotting.

Results: RIPC significantly improved neurological scores and reduced infarct volume and neuronal apoptosis in rats subjected to I/R injury. OGD preconditioning significantly reduced neuronal apoptosis and improved cell viability after I/R injury on days 3 and 7 after OGD/R. However, the neuroprotective effect was reversed by DAPT in vivo and attenuated by Notch1-RNAi in vitro. RIPC significantly upregulated the expression of proteins related to the Notch1 and NF-KB pathways. NF-KB signaling pathway activity was suppressed by a Notch1 signaling pathway inhibitor and Notch1-RNAi.

Conclusions: The neuroprotective effect of RIPC against cerebral I/R injury was associated with preactivation of the Notch1 and NF-KB pathways in neurons. The NF-KB pathway is a downstream target of the Notch1 pathway in RIPC and helps protect focal cerebral I/R injury.

Keywords: Ischemia-reperfusion injury, Remote ischemic preconditioning, Neuroprotection, Notch1 pathway, NFkappa B, Cross reaction

\footnotetext{
*Correspondence: linchunshui2014@163.com

'Nanfang Hospital, Southern Medical University, Guangzhou 510515, China

Full list of author information is available at the end of the article
}

(c) The Author(s). 2019 Open Access This article is distributed under the terms of the Creative Commons Attribution 4.0 International License (http://creativecommons.org/licenses/by/4.0/), which permits unrestricted use, distribution, and reproduction in any medium, provided you give appropriate credit to the original author(s) and the source, provide a link to the Creative Commons license, and indicate if changes were made. The Creative Commons Public Domain Dedication waiver (http://creativecommons.org/publicdomain/zero/1.0/) applies to the data made available in this article, unless otherwise stated. 


\section{Introduction}

Stroke remains a leading cause of death and disability worldwide, and few clinically approved treatments are available for its most common form, ischemic stroke. Ischemic preconditioning (IPC) is considered an effective prophylactic treatment for ischemic stroke. Many basic and clinical studies have confirmed that IPC can produce a significant neuroprotective effect by initiating endogenous protective mechanisms, effectively reducing cerebral ischemia-reperfusion injury [1-3]. Among the many ischemic preconditioning methods, remote ischemic preconditioning (RIPC) is considered a promising one, because it uses a simple, noninvasive procedure and is nearly ready for clinical practice. Numerous clinical trials in recent years have shown that RIPC can effectively induce cerebral ischemic tolerance, thereby reducing ischemia-reperfusion injury and improving patient prognosis. However, the underlying mechanism is not fully understood. Understanding the mechanisms underlying RIPC-induced neuroprotection will help minimize ischemic brain injury.

Evidence suggests that the protective effects of RIPC against ischemia are mainly related to neuronal, humoral, and immunity-related pathways, as well as a variety of biomolecules and signaling pathways. The Notch signaling pathway is a highly conserved pathway widely found in vertebrates and nonvertebrates, regulating the differentiation and development of cells, tissues, and organs through interactions with adjacent cells; the pathway plays an important regulatory role in cell proliferation, differentiation, and apoptosis. Previous studies suggest that the Notch signaling pathway is involved in cerebral ischemic injury, and blocking Notch signaling can reduce neuronal cell apoptosis and improve prognosis [4]. However, recent studies have confirmed that Notch signaling preactivation may be involved in neuronal ischemic tolerance to subsequent lethal ischemia-reperfusion injury [5-7]. It was reported that pretreatment with sevoflurane and isoflurane could reduce neuronal cell apoptosis during ischemia-reperfusion injury and promote proliferation of neural stem cells by activating the Notch signaling pathway; the protective effect of pretreatment was reversed if Notch signaling was blocked $[5,8]$. Zhou et al. also demonstrated that ischemic preconditioning could reduce myocardial ischemia and reperfusion injury by activating the Notch signaling pathway [9]. Recent research confirmed that RIPC increased Notch signaling activity and promoted arteriogenesis in the ischemic rat brain [10].

Evidence confirms that NF- $\mathrm{KB}$ plays an important role in the formation of cerebral ischemic tolerance by regulating the transcriptional expression of target genes and the activity of other pathways involved in cerebral ischemia. Ischemic preconditioning can activate NF- $\mathrm{BB}$ signaling, increase the expression of NF-kB , and enhance the DNA-binding activity of that protein in neurons, thus inducing ischemic tolerance to subsequent lethal ischemia and hypoxia injury. Moreover, the NF- $\mathrm{kB}$ inhibitor PDTC can reverse the neuroprotective effect of IPC $[11,12]$. Studies have shown that the gene NF-kB is a downstream target of Notch signaling pathway. The Notch signaling pathway regulates the activation of DNA binding of NF- $\kappa B$ by regulating I $\mathrm{KB}$ kinase (IKK), thus affecting the expression of NF-kB-dependent target genes $[13,14]$. Additionally, the Notch ligand Jagged-1 is regulated by NF-kB [15]. A certain level of Notch signaling is essential to maintain the activity of NF- $\mathrm{kB}$, and the activity of NF- $\mathrm{KB}$ decreases with the reduction of Notch signal intensity, showing a synergistic trend [16-18].

Accordingly, the aim of this study was to investigate the neuroprotective effects of RIPC on cerebral ischemia-reperfusion injury and the roles of the Notch1 and NF-kB signaling pathways in RIPC-induced neuroprotection.

\section{Methods \\ Animals}

Adult male Sprague Dawley rats (250-280 g, Laboratory Animal Center of Southern Medical University, Guangzhou, China) were housed with free access to standardized chow and tap water under diurnal lighting conditions (12-h/12-h light/dark cycle). All experimental protocols and animal-related procedures were carried out in accordance with the US National Institutes of Health's Guide for the Care and Use of Laboratory Animals (NIH Publication No. 85-23, revised 1996) and approved by the Experimental Animal Ethics Committee of Southern Medical University.

\section{Induction of remote ischemic preconditioning (RIPC)}

RIPC was induced in the fixed left hindlimb of rats using a modified blood pressure cuff. The cuff was inflated to 180-200 mmHg to block the blood flow through the left hindlimb femoral artery for $5 \mathrm{~min}$ (ischemia) followed by a 5-min deflation (reperfusion). Interruption of the blood supply to the hindlimb was confirmed by the disappearance of the pulse wave, a reduced body temperature in the limb, and cyanosis of the skin on the limb. The RIPC protocol consisted of 4 cycles per day of $5 \mathrm{~min}$ of ischemia followed by $5 \mathrm{~min}$ of reperfusion for 3 days before middle cerebral artery occlusion and reperfusion.

\section{Middle cerebral artery occlusion and reperfusion (MCAO/ R) model}

Rats were fasted for $12 \mathrm{~h}$ before surgery but remained free to drink water during that time. All rats were anesthetized by intraperitoneal injection of $10 \%$ chloral hydrate $(350 \mathrm{mg} / \mathrm{kg})$. MCAO/R surgery was conducted as described previously, with slight modification [19]. 
Briefly, the right common carotid artery (CCA), external carotid artery (ECA), internal carotid artery (ICA), and junction were carefully exposed and isolated through a midline neck incision under aseptic conditions. Siliconecoated sutures (head diameter $0.36 \pm 0.02 \mathrm{~mm}$, Beijing Sunbio Biotech Co., Ltd., Beijing, China) were inserted into the external carotid incision and passed through the ICA to the beginning of the middle cerebral artery to block its blood flow for $1 \mathrm{~h}$ followed by $24 \mathrm{~h}$ of reperfusion. The ipsilateral cerebral blood flow was monitored by laser Doppler flowmetry. The surgery was considered successful as long as the cerebral blood flow decreased by $\geq 70 \%$ from baseline. During the operation, rectal temperature was continuously monitored and maintained at $37 \pm 0.5^{\circ} \mathrm{C}$ with thermostatic surgery pad. After surgery, all rats were placed on warm blankets until recovery.

\section{Intracerebroventricular drug administration}

Intracerebroventricular injection of the $\gamma$-secretase inhibitor DAPT or its vehicle, dimethyl sulfoxide (DMSO), was carried out as described previously [20, 21] Briefly, the rats were fixed in a stereotaxic apparatus ( $C$ type, ZH-Lanxing, Lihua Electronic Technology Development Co., Ltd., Xuzhou, China) after being anesthetized with $10 \%$ chloral hydrate $(350 \mathrm{mg} / \mathrm{kg}$, intraperitoneal injection). The coordinates of the right lateral ventricle were $0.8 \mathrm{~mm}$ posterior to the bregma, $1.5 \mathrm{~mm}$ from the midline, and $4.0 \mathrm{~mm}$ beneath the skull surface. Intracerebroventricular injections were performed using a Hamilton syringe attached to a 30 -gauge needle $30 \mathrm{~min}$ prior to the MCAO surgery. DAPT (Cell Signaling Technology, Beverly, MA, USA; $50 \mu \mathrm{g} / 3 \mu \mathrm{l} / \mathrm{rat}$, dissolved in $90 \%$ DMSO) or vehicle (3 $\mu \mathrm{l}, 90 \%$ DMSO) was administered intracerebroventricularly at a rate of $1 \mu \mathrm{l} / \mathrm{min}$. After injection, the needle was kept in place for $5 \mathrm{~min}$ and then pulled out slowly. The craniotomies were closed with sterile bone wax, and the skin was sutured with silk thread after being disinfected with $75 \%$ ethanol.

\section{Assessment of neurological deficits}

Neurological deficits were assessed after $24 \mathrm{~h}$ of reperfusion by an investigator who did not know the experimental groupings. The assessment was carried out using a 6-item scale with 4 levels for each item, based mainly on Garcia's scale [22].

\section{Quantification of brain infarct volume}

After the evaluation of neurological deficits, the rats were sacrificed under deep anesthesia. The brains were harvested and sectioned into 2-mm-thick coronal slices using a rat brain slice mold (Beijing Sunbio Biotech Co., Ltd., Beijing, China). The brain slices were stained with 1\% 2,3,5-triphenyl-tetrazolium chloride solution (TTC,
Sigma-Aldrich, St. Louis, MO, USA) in a dark, thermostatically controlled water bath at $37^{\circ} \mathrm{C}$ for $15 \mathrm{~min}$ with agitation every $5 \mathrm{~min}$. After being fixed with $4 \%$ paraformaldehyde solution for $24 \mathrm{~h}$, the brain slices were scanned to obtain images, and the brain infarct area on each slice was calculated using ImageJ software. The infarct volume (\%) for the brain was calculated with the following formula: (the volume of the contralateral hemisphere-the volume of the nonlesioned ipsilateral hemisphere)/(the volume of the contralateral hemisphere $\times 2)[23,24]$.

Primary culture and lentiviral transfection of hippocampal neurons

Primary hippocampal neurons were prepared from the hippocampi of Sprague Dawley rat embryos at 17 days of gestation using a previously described protocol [25]. Briefly, embryonic hippocampal tissues were gently minced into pieces using a sterile scalpel and incubated with papain solution at $37^{\circ} \mathrm{C}$ for $30 \mathrm{~min}$, followed by DNAzyme I for $3 \mathrm{~min}$. DMEM/10\% FBS was used to stop the enzymatic reaction. The cells were seeded onto Poly-L-lysine-coated plastic 6-well culture plates at a seeding density of $1-2 \times 10^{5} / \mathrm{cm}^{2}$ per well. After $4 \mathrm{~h}$, the plating medium (DMEM/F12 + 2\% B-27 + 2\% FBS) was replaced with Neurobasal feeding medium (Neurobasal $\mathrm{A}+2 \% \mathrm{~B}-27+1 \%$ L-glutamine). The neurons were fed every 3 days by removing half of the old media and replacing it with the same volume of fresh Neurobasal feeding media. After 7 days of culture, the neurons were labeled with an immunofluorescent MAP-2 antibody and prepared for follow-up experiments. A lentivirus containing the sh-Notch1 plasmid was used to transfect hippocampal neurons to interfere with the expression of the Notch gene. Lentiviral interference efficiency was measured using qRT-PCR and Western blotting 3 days after transfection.

\section{Oxygen-glucose deprivation (OGD) pretreatment and oxygen-glucose deprivation and reoxygenation (OGD/R) model construction}

For preconditioning in vitro, hippocampal neurons were subjected to transient sublethal oxygen-glucose deprivation (OGD) according to previously described protocols [26, 27]. Briefly, hippocampal cultures were incubated in deoxygenated Neurobasal medium without glucose (Invitrogen, Carlsbad, CA, USA) under anoxic conditions $\left(85 \% \mathrm{~N}_{2}, 10 \% \mathrm{H}_{2}, 5 \% \mathrm{CO}_{2}\right)$ at $37^{\circ} \mathrm{C}$ in an anaerobic incubator for $30 \mathrm{~min}$. Then, the hippocampal cultures were cultured in the original Neurobasal medium and replaced in a normoxic incubator for $24 \mathrm{~h}$. For the oxygen-glucose deprivation and reoxygenation (OGD/R) model, hippocampal cultures were exposed to OGD again for $3 \mathrm{~h}$ followed by a 24 -h recovery in the 
original Neurobasal medium in a normoxic incubator (5\% $\mathrm{CO}_{2}$ and $95 \%$ air).

\section{Cell viability assay}

The viability of hippocampal neurons was quantified using a Cell Counting Kit-8 (CCK-8, Beijing Sunbio Biotech Co., Ltd., Beijing, China) according to the manufacturer's protocol. Briefly, neurons were seeded onto a 96-well plate at a density of 2000 cell per well, with 6 replicate wells per group. The CCK-8 reaction solution was directly added to the medium in a volume of $10 \mu \mathrm{l}$ per well. Finally, the number of viable cells was estimated by measuring the optical density $(O D)$ at $450 \mathrm{~nm}$ using a multidetection microplate reader (Molecular Devices, Sunnyvale, CA) after $4 \mathrm{~h}$ of incubation at $37^{\circ} \mathrm{C}$.

\section{Apoptosis detection by flow cytometry}

Neuronal apoptosis was detected using fluorescence-activated cell sorting (FACS) with Annexin V-FITC/PI staining. Briefly, hippocampal neurons were harvested and resuspended in a binding buffer at a cell concentration of approximately $1 \times 10^{6} / \mathrm{ml}$ after OGD/R or other treatments in different groups. An Annexin V-FITC Apoptosis Detection Kit (Keygen Biotech, Jiangsu, China) was used following the manufacturer's protocol. Annexin V-FITC $(1 \mu \mathrm{l})$ and propidium iodide $(2 \mu \mathrm{l})$ were added to each $100 \mu \mathrm{l}$ of cell suspension. After reacting for $15 \mathrm{~min}$ at room temperature in a dark environment, apoptotic cells were detected by FACS (BD Calibur; BD Biosciences, San Jose, CA, USA).

\section{Immunofluorescent staining}

TUNEL and NeuN double immunofluorescence staining were used to detect neuronal apoptosis in the brain hippocampus area of the rats. For double immunofluorescence labeling, an Apoptosis Assay Kit (TUNEL, Beijing Sunbio Biotech Co., Ltd., Beijing, China) and anti-NeuN monoclonal antibody (Cell Signaling Technology, Beverly, MA, USA) were used as described [28]. In brief, brain sections measuring $40 \mu \mathrm{m}$ in thickness were incubated with antiNeuN primary antibodies (1:200 dilution) at $4{ }^{\circ} \mathrm{C}$ overnight, followed by a 1-h incubation with an immunofluorescently labeled secondary antibody (1: 500 dilution) at room temperature before TUNEL labeling. For TUNEL labeling, sections were incubated with a reaction mixture containing terminal deoxynucleotidyl transferase (TdT) and fluorescein-conjugated deoxyuridine triphosphate (dUTP) for $2 \mathrm{~h}$ at $37^{\circ} \mathrm{C}$. The nuclei were stained for $5 \mathrm{~min}$ with Hoechst stain at room temperature. All immunofluorescent labeling was detected using an automatic fluorescence microscope (OLYMPUS DP80; Olympus Co., Tokyo, Japan). Three sections per rat were examined, and the apoptotic neurons were counted in the images using the program ImageJ.

\section{Quantitative real-time polymerase chain reaction (qRT- PCR)}

The expression level of Notch 1 mRNA was detected by qRT-PCR. Briefly, total RNA was extracted by Trizol (Invitrogen, USA) after removing the genomic DNA using DNase I (Promega, USA) following the manufacturer's instructions. The total RNA was reverse-transcribed to cDNA using a Reverse Transcription System (Promega, USA). Quantitative real-time PCR was performed on ABI Prism 7500 (Applied Biosystems) using SYBR $^{\circ}$ Green qPCR SuperMix-UDG (Invitrogen, USA). The cycling conditions were as follows: $2 \mathrm{~min}$ at $50^{\circ} \mathrm{C}$ and then $2 \mathrm{~min}$ at $95^{\circ} \mathrm{C}$ followed by 40 cycles of $15 \mathrm{~s}$ at $95^{\circ} \mathrm{C}$ and $30 \mathrm{~s}$ at $60^{\circ} \mathrm{C}$. The PCR results were quantified using the threshold cycle (Ct) method.

\section{Western blot analysis}

Protein expression was assessed by Western blotting. Briefly the ischemic penumbra tissues were collected according to a previously described method [29]. Proteins were extracted using a Total Protein Extraction Kit (Sangon Biotech, Shanghai, China), and the concentration was determined using a BCA protein assay kit (Nanjing Keygen Biotech, Jiangsu, China) according to the manufacturer's protocol. The total protein was separated by gel electrophoresis (7.5-12.5\% SDS-PAGE) and transferred to polyvinylidene fluoride (PVDF) membranes. The membranes were blocked in 5\% fat-free milk powder for $1 \mathrm{~h}$ at room temperature, followed by an overnight incubation at $4{ }^{\circ} \mathrm{C}$ with rabbit anti-rat primary antibodies against NICD (1:1000 dilution, Cell Signaling Technology), Hes1 (1:1000 dilution, Cell Signaling Technology), IKK $\beta$ (1:1000 dilution, Abcam), Phospho-IKK $\alpha /$ $\beta$ (1:1000 dilution, Cell Signaling Technology), PhosphoNF-kB p65 (1:1000 dilution, Cell Signaling Technology), NF-kB p65 (1:1000 dilution, Cell Signaling Technology), Bcl-2 (1:1000 dilution, Cell Signaling Technology), Bax (1:1000 dilution, Cell Signaling Technology), and $\beta$-actin (1:1000 dilution, Abcam). The membranes were washed four times in PBST (0.1 M PBS containing 0.3\% Triton $\mathrm{X}-100$ ), followed by $1 \mathrm{~h}$ of incubation with horseradish peroxide-conjugated anti-rabbit IgG secondary antibody at room temperature. All experiments were carried out at least three times. Chemiluminescence images were acquired using darkroom imaging techniques, and the relative quantity of proteins was analyzed using ImageJ and normalized to that of loading controls.

\section{Statistical analysis}

Data were expressed as means \pm SEMs. Neurological scores were presented as the median and interquartile 
range and analyzed using the Kruskal-Wallis $\mathrm{H}$ test. When the Kruskal-Wallis $\mathrm{H}$ test showed a significant difference, the Mann-Whitney $U$ test with the Bonferroni correction was applied. All other data were analyzed using one-way ANOVA followed by the least significant difference (LSD) or Bonferroni's method to evaluate the differences between groups if the variance was homogeneous, otherwise, the Games-Howell test was used. $P<$ 0.05 was considered statistically significant. Statistical analysis was performed using the statistical program SPSS 23.0 (SPSS, IBM, Chicago, IL, USA).

\section{Results}

Effect of RIPC on neurological deficit scores and infarct volume in rats after $M C A O / R$

Rats subjected to $\mathrm{MCAO} / \mathrm{R}$ injury showed a significant motor behavioral deficit in the contralateral limbs. Neurological deficit scores were significantly decreased in the
$\mathrm{MCAO/R}$ group. RIPC significantly increased neurological scores in comparison with those of the $\mathrm{MCAO} / \mathrm{R}$ group $(P<0.01$, Fig. 1c), suggesting a neuroprotective effect of RIPC in rats after $\mathrm{MCAO} / \mathrm{R}$.

To evaluate brain infarct volume, we used TTC staining $24 \mathrm{~h}$ after reperfusion. The infarct volume was reduced by $40.2 \%$ in the RIPC + MCAO/R group compared with the $\mathrm{MCAO} / \mathrm{R}$ group $(P<0.01$, Fig. $1 \mathrm{~b})$. No infarction or edema formation was observed in either the sham group or the RIPC group (Fig. 1a).

Effects of RIPC on the expression of NICD, Hes1, IKK $\beta$, and NF-KB p65 in the ischemic penumbra after MCAO/R

To explore the effects of RIPC on the Notch and NF- $k B$ signaling pathways in the brain after $\mathrm{MCAO} / \mathrm{R}$, we conducted Western blots to investigate the expression of NICD, Hes1, IKK $\beta$, and NF- $k B$ p65 in the ischemic penumbra after $24 \mathrm{~h}$ of reperfusion. The RIPC group had

\section{A}

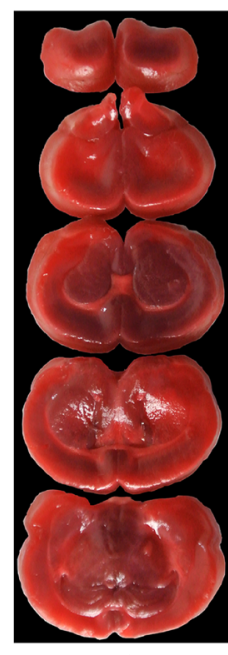

$s^{r 05}$
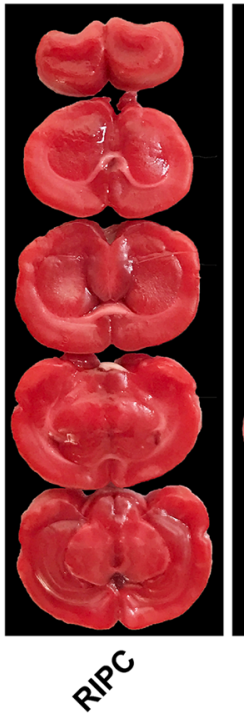
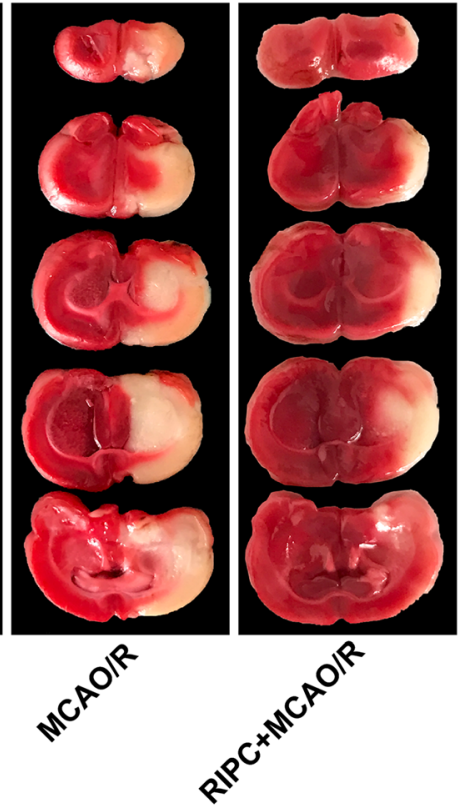

B

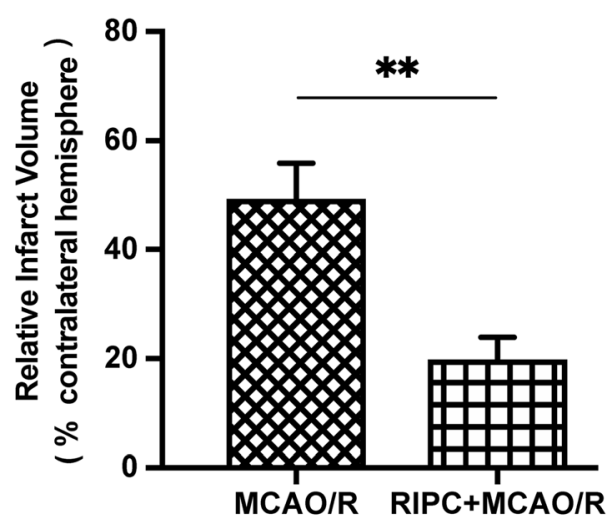

C

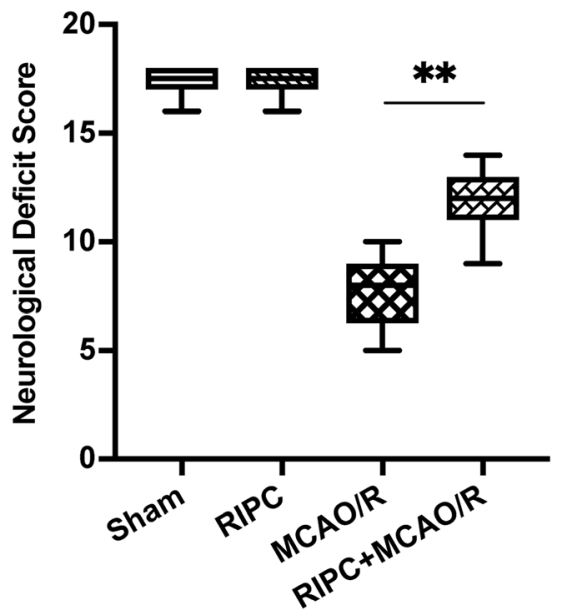

Fig. 1 Effect of RIPC on neurological deficit scores and infarct volume in rats after MCAO/R. The neurological deficit scores and brain infarction volume were evaluated $24 \mathrm{~h}$ after reperfusion in rats in the four groups. a Cerebral infarct images (white, infarct tissue; red, noninfarct tissue) stained using 2,3,5-triphenyltetrazolium chloride in coronal sections of rat brains. b Brain infarct volume presented as a percentage of the intact hemisphere. Data are presented as the means \pm SEM. ${ }^{* *} P<0.01$ vs. the MCAO/R group. $\mathbf{c}$ Neurological scores are presented as the median (interquartile range). ${ }^{* *} P<0.01 \mathrm{vs}$. the $\mathrm{MCAO} / \mathrm{R}$ group 
higher expression of NICD, Hes1, and NF-kB p65 than the sham group. In comparison with the $\mathrm{MCAO} / \mathrm{R}$ group, RIPC significantly upregulated the expression of NICD, Hes1, IKK $\beta$, and NF-kB p65 in the RIPC + $\mathrm{MCAO} / \mathrm{R}$ group, suggesting that RIPC plays a role in activating the Notch and NF- $\mathrm{KB}$ signaling pathways in the brain after $\mathrm{MCAO} / \mathrm{R}$ (Fig. 2a, b).

Effects of OGD preconditioning on the levels of cell viability and cell apoptosis in primary hippocampal neurons after OGD/R injury

Hippocampal neurons were identified by immunofluorescent MAP-2 antibody (Fig. 3a). Notch1 RNA interference efficiency was identified by qRT-PCR and Western blotting (Fig. 3b, c, d). Neuronal viability was assessed using the CCK- 8 assay. After primary hippocampal neurons were subjected to $3 \mathrm{~h}$ of OGD followed by $24 \mathrm{~h}$ of recovery, cell viability was significantly decreased compared with that of the control cell group on days 1, 3, and 7 after OGD/R (Fig. 3e). By contrast, cell viability was not affected by $30 \mathrm{~min}$ of OGD preconditioning. Furthermore, OGD preconditioning significantly increased cell viability after OGD/R injury on day 3 and day 7 after $\mathrm{OGD} / \mathrm{R}$, but the neuroprotective effect was attenuated by Notch1-RNAi $(P<0.05$, Fig. 3e).

To determine the effects of OGD preconditioning on OGD/R-induced apoptosis of hippocampal neurons, we used FACS with Annexin V-FITC/PI staining. The results showed that neuronal apoptosis was significantly increased after OGD/R injury. No significant neuronal apoptosis was observed after OGD preconditioning compared with the control cell group. OGD preconditioning significantly reduced neuronal apoptosis on day 3 and day 7 after $\mathrm{OGD} / \mathrm{R}(P<0.05$, Fig. 3f $)$. However, the neuroprotective effect was attenuated by Notch1-RNAi, suggesting an important role of the Notch1 signaling pathway in the neuroprotection provided by OGD preconditioning (Fig. 3f).

\section{Effects of DAPT on MCAO/R injury and Notch1-RNAi on $\mathrm{OGD} / \mathrm{R}$ injury in vivo and in vitro, respectively}

DAPT significantly increased neurological scores and reduced infarct volume and neuronal apoptosis after direct lethal MCAO/R injury in vivo (Fig. 4a-e). Notch1-RNAi significantly increased hippocampal neuronal cell viability and reduced neuronal apoptosis on day 3 and day 7 following direct lethal OGD/R injury in vitro (Fig. 4f and Fig. 5a).

Effects of OGD preconditioning on the expression of NICD, Hes 1, p-IKK a/ $\beta$, p-NF-KB p65, Bcl-2, and Bax in primary hippocampal neurons after $\mathrm{OGD} / \mathrm{R}$

To determine the effect of OGD preconditioning on the Notch and NF- $\mathrm{kB}$ signaling pathways in primary hippocampal neurons after $\mathrm{OGD} / \mathrm{R}$, we used Western blot analysis to examine the expression of NICD, Hes1, p-IKK $\alpha / \beta$, p-NF- $\mathrm{kB}$ p65, Bcl-2, and Bax in primary hippocampal neurons after OGD/R. The OGDPC group had significantly higher expression of NICD, Hes1, p-IKK $\alpha / \beta$, and p-NF- $\kappa B$ p65 than the control cell group. In comparison with the $\mathrm{OGD} / \mathrm{R}$ group, OGD preconditioning significantly upregulated the expression of NICD, Hes1, p-IKK $\alpha / \beta, p-N F-k B$ $\mathrm{p} 65$, and $\mathrm{Bcl}-2$ in the $\mathrm{OGD}+\mathrm{OGD} / \mathrm{R}$ group, suggesting that OGD preconditioning plays a role in activating the Notch and NF- $\mathrm{BB}$ signaling pathways in primary hippocampal neurons. However, the expression of Bax decreased in the $\mathrm{OGD}+\mathrm{OGD} / \mathrm{R}$ group
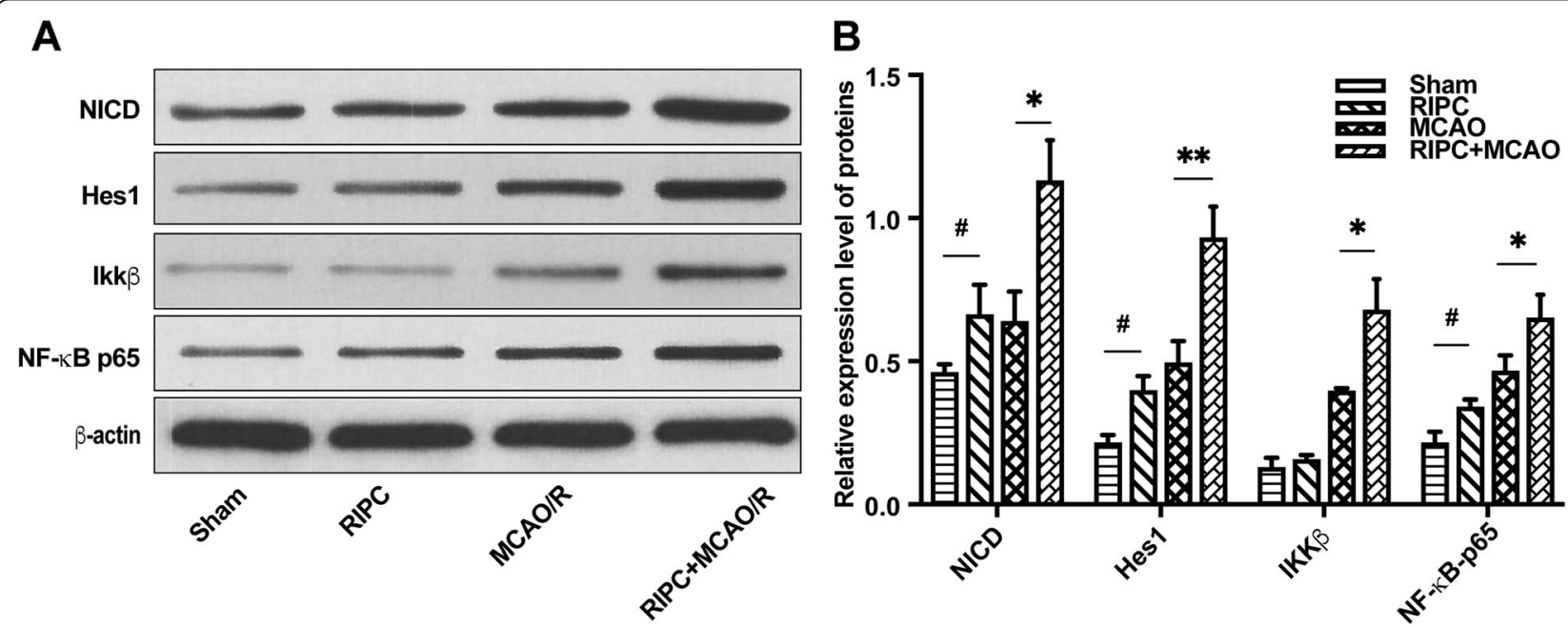

Fig. 2 RIPC activated the Notch and NF-KB signaling pathways in the ischemic penumbra after MCAO/R. a Protein bands of NICD, Hes1, IKKB, NF$\mathrm{KB}$ p65, and $\beta$-actin from Western blot analysis. b RIPC significantly upregulated the expression of proteins related to the Notch and NF- $\mathrm{KB}$ signaling pathways. Data are presented as the means \pm SEM. ${ }^{*} P<0.05,{ }^{* *} P<0.01$, vs. the MCAO/R group; ${ }^{\#} P<0.05$ vs. the sham group 


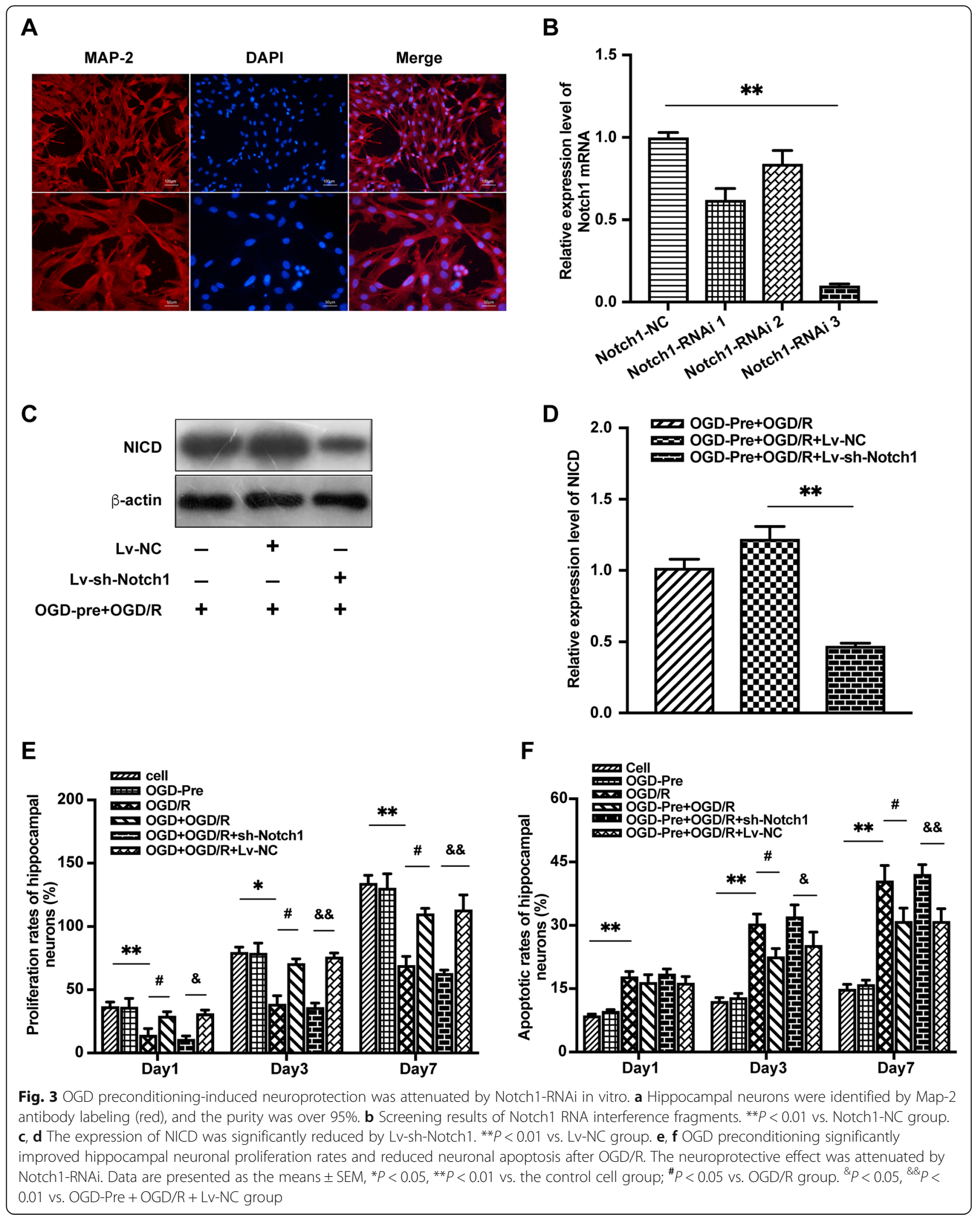




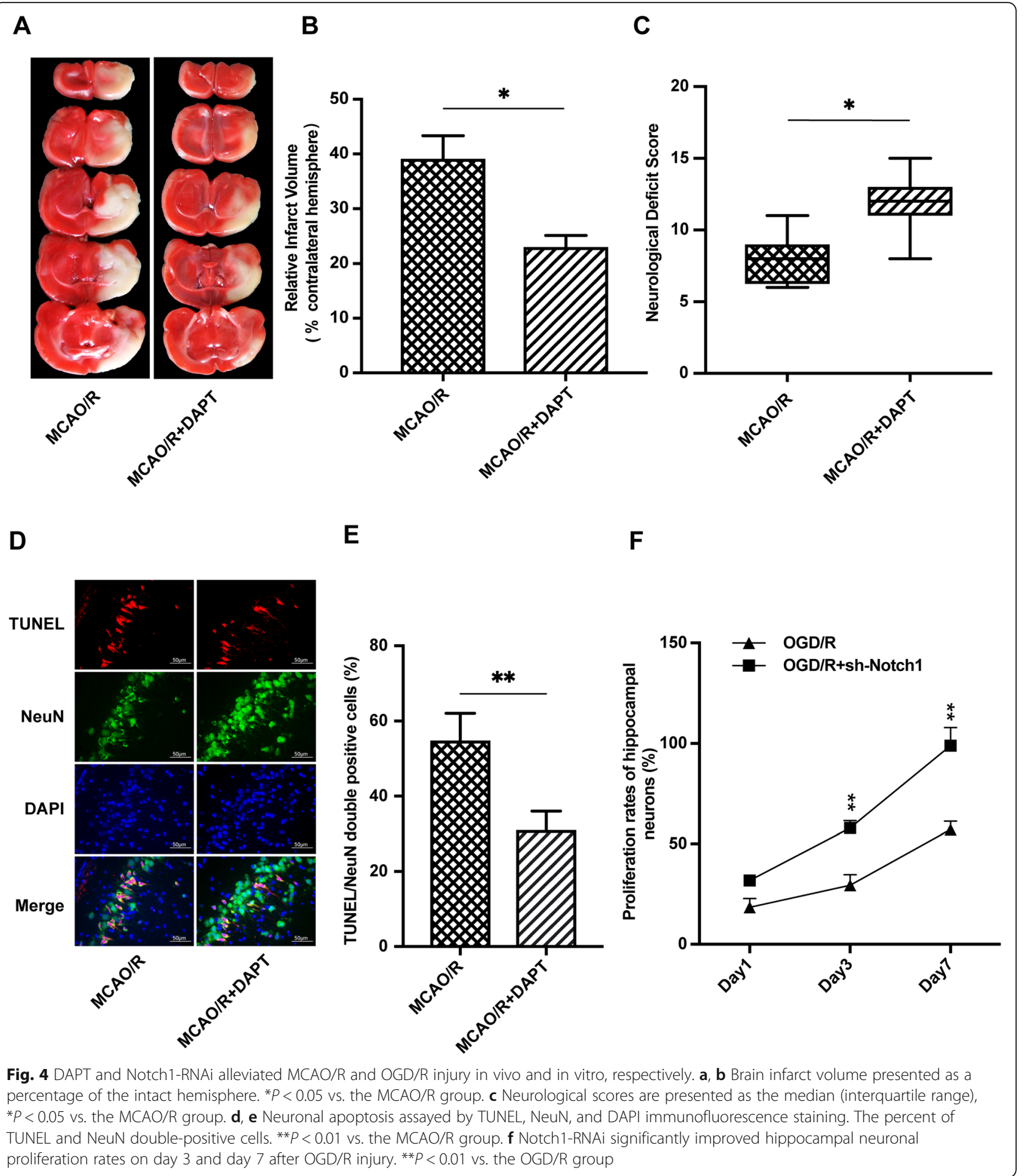

compared to the OGD/R group. The expression of $\mathrm{p}$ IKK $\alpha / \beta$ and $p-N F-\kappa B$ p65 was suppressed by Notch1-RNAi, suggesting that the NF- $\mathrm{kB}$ signaling pathway was regulated by the Notch1 signaling pathway in primary hippocampal neurons after OGD/R (Fig. 5b-d).
RIPC-induced neuroprotection was attenuated by the Notch1 signaling pathway inhibitor DAPT in vivo

To further confirm whether RIPC-induced neuroprotection is mediated by the Notch1 signal pathway, we administered the Notch1 pathway inhibitor DAPT to the rats by the intracerebroventricular route and evaluated by neurological 


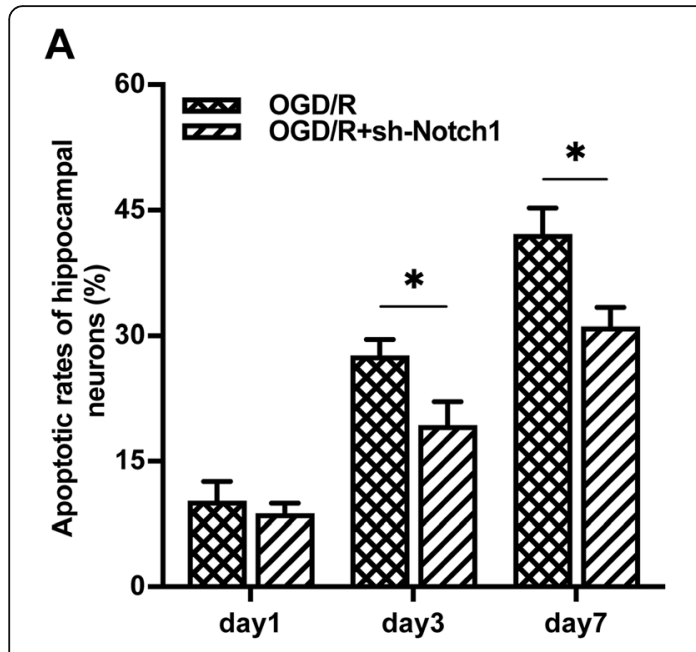

B



C
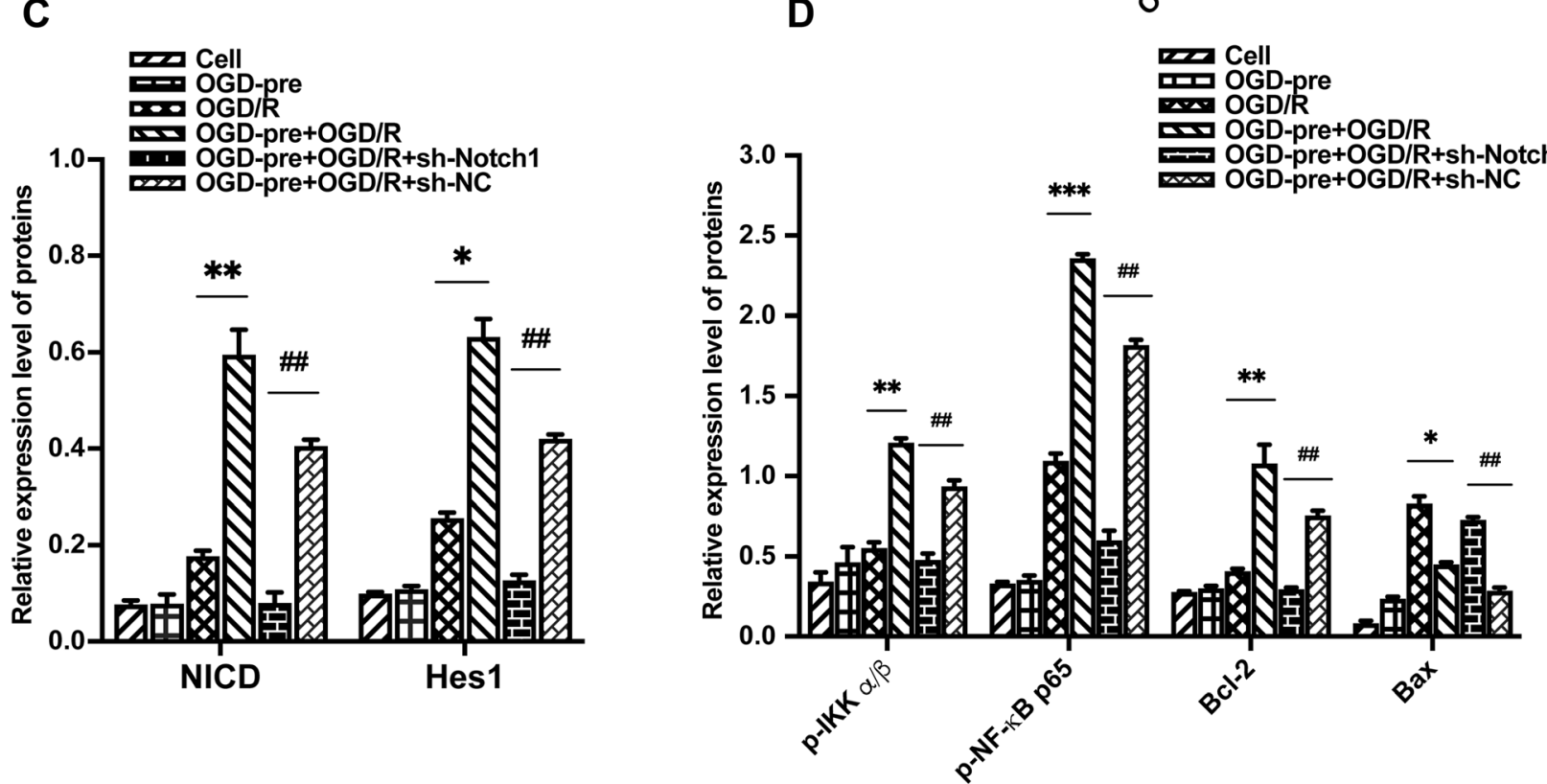

Fig. 5 In the hippocampal neuronal OGD/R model, OGD-preconditioning activated the Notch1 and NF-KB signaling pathways, and the NF-KB signaling pathway was suppressed by Notch1-RNAi. a Notch1-RNAi significantly reduced neuronal apoptosis on day 3 and day 7 following direct lethal OGD/R injury in vitro, ${ }^{*} P<0.05$ vs. OGD/R group. b Protein bands of NICD, Hes1, p-IKK a/ $\beta$, p-NF-KB p65, Bcl-2, Bax, and $\beta$-actin from Western blot analysis. $\mathbf{c}$, $\mathbf{d}$ OGD-preconditioning significantly upregulated the expression of proteins related to the Notch1 and NF-KB signaling pathways after OGD/R. The expression of $\mathrm{p}-\mathrm{IKK} a / \beta$ and $\mathrm{p}-\mathrm{NF}-\mathrm{KB}$ p65 was suppressed by Notch1-RNAi. Data are presented as the means \pm SEM in c and $\mathbf{d} ;{ }^{*} P<0.05,{ }^{*} P<0.01,{ }^{* *} P<0.001$ vs. the OGD/R group; ${ }^{\# \#} P<0.01$ vs. OGD-Pre + OGD/R + sh-NC group

deficit scores and relative brain infarct volume. Neurological deficit scores were significantly higher in the RIPC + $\mathrm{MCAO} / \mathrm{R}$ group than in the $\mathrm{MCAO} / \mathrm{R}$ group. However, the neurological deficit scores significantly decreased when the Notch1 signaling pathway was inhibited by DAPT $(P<$ 0.01, Fig. 6c). RIPC significantly decreased the relative brain infarct volume in comparison with that of the MCAO/R group. However, the neuroprotective effect was reversed by 




DAPT. These results indicated that Notch1 signaling activation contributes to the neuroprotection provided by RIPC $(P<0.01$, Fig. 6a, b).

RIPC significantly reduced hippocampal neuronal cell apoptosis in rats after $M C A O / R$, but the neuroprotective effects were attenuated by an inhibitor of the Notch1 signaling pathway

A NeuN/TUNEL assay was used to elucidate the effect of RIPC on neuronal apoptosis in the rat hippocampus after $\mathrm{MCAO} / \mathrm{R}$. TUNEL and NeuN double immunofluorescence staining represents the rate of apoptosis. We found that MCAO/R injury increased the number of NeuN/TUNEL-positive cells in the hippocampus area, while RIPC significantly downregulated the proportion of NeuN/TUNEL-positive cells compared with that of the $\mathrm{MCAO} / \mathrm{R}$ group. However, the antiapoptotic effect was attenuated by DAPT $(P<0.01$, Fig. $7 \mathrm{a}, \mathrm{b})$. These results illustrate that RIPC significantly reduced hippocampal neuronal apoptosis in rats after $\mathrm{MCAO} / \mathrm{R}$. However, the neuroprotective effects were attenuated by an inhibitor of the Notch signaling pathway.

The NF-KB signaling pathway is activated by RIPC but attenuated by the Notch1 pathway inhibitor DAPT

To determine whether Notch1 modulates the activity of the NF- $\mathrm{kB}$ signaling pathway during RIPC, we measured the expression of $\mathrm{p}-\mathrm{IKK} \alpha / \beta, \mathrm{p}-\mathrm{NF}-\mathrm{kB}$ p 65 , $\mathrm{Bcl}-2$, and $\mathrm{Bax}$ in the ischemic penumbra of rats that received DAPT compared to rats that did not. RIPC significantly upregulated the expression of NICD, Hes1, p-IKK $\alpha / \beta$, p-NF-kB p65, and Bcl-2 but 


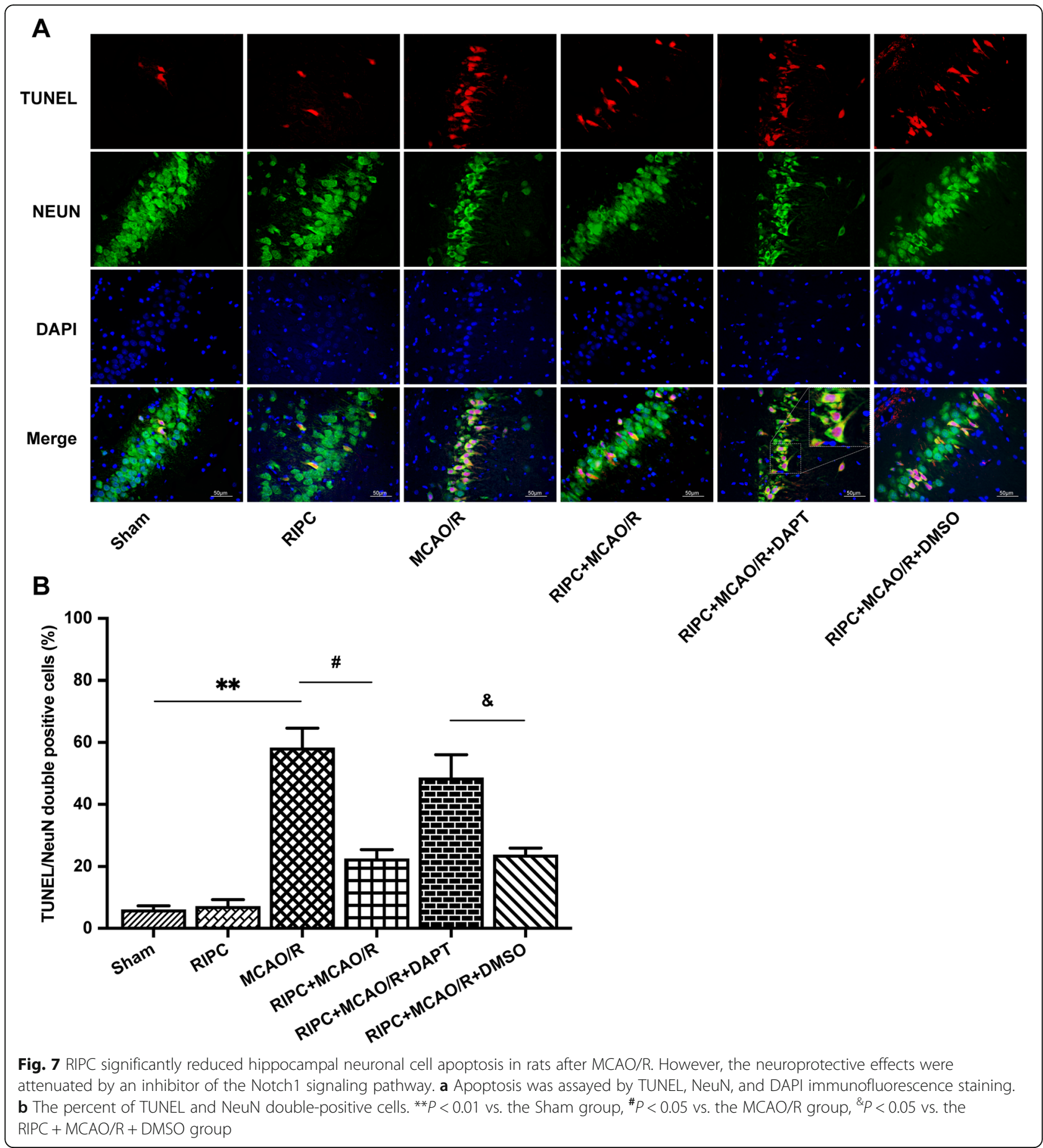

suppressed the expression of Bax. However, DAPT markedly suppressed the RIPC-induced upregulation of NICD and Hes1 and attenuated the expression of p-IKK $\alpha / \beta$, p-NF- $\mathrm{KB}$ p65, and Bcl-2 (Fig. 8c-e). These results suggested that RIPC activated the Notch and NF- $k B$ signaling pathways in rats after $\mathrm{MCAO} / \mathrm{R}$. NF$\kappa B$ pathway activity was suppressed by the Notch1 pathway inhibitor DAPT in vivo.

\section{Discussion}

The aim of this study was to investigate the underlying mechanism of RIPC-mediated neuroprotection against cerebral ischemia-reperfusion injury and the roles of the Notch1 and NF- $\mathrm{kB}$ signaling pathways in RIPC-induced cerebral ischemic tolerance. Solid evidence from diverse preclinical models and species and clinical trials has demonstrated that limb RIPC can effectively alleviate 
A


B

D
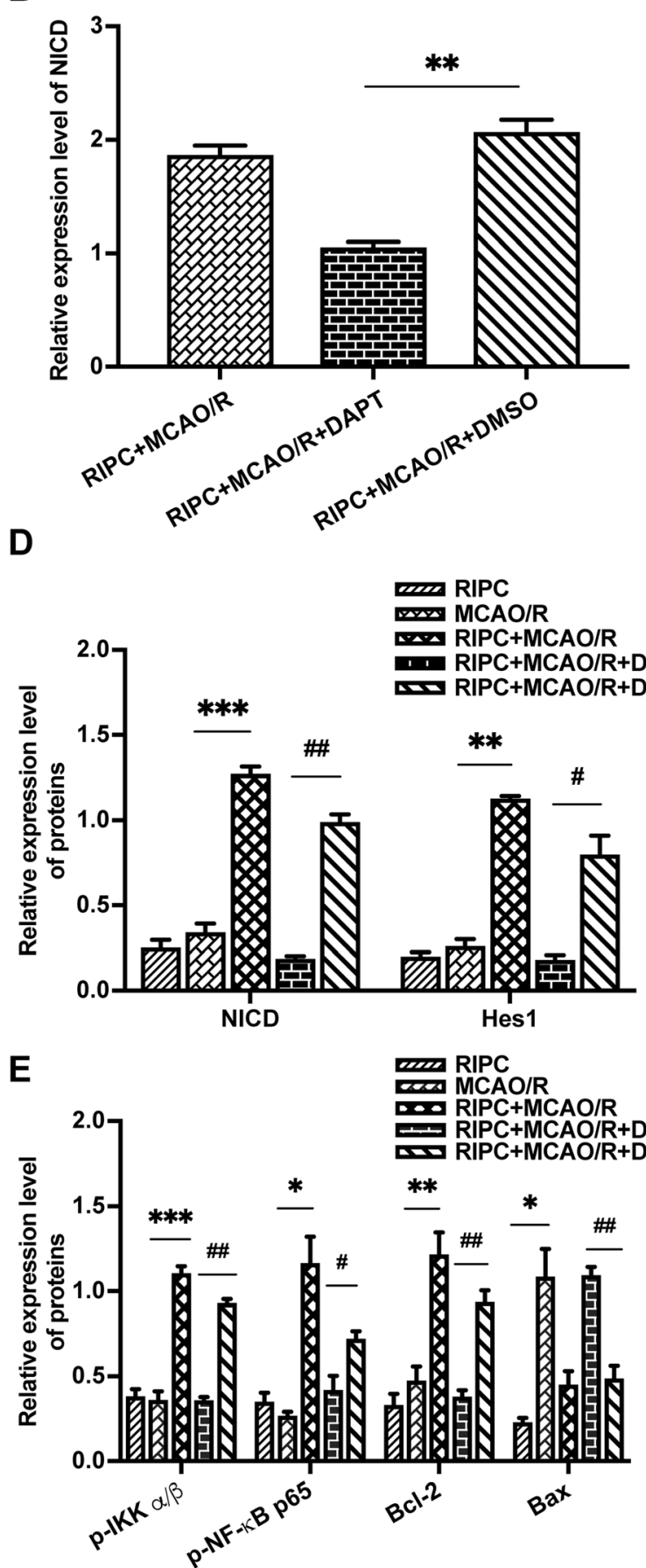

Fig. 8 RIPC activated the Notch1 and NF-KB signaling pathways in rats after MCAO/R. NF-KB signaling pathway activity was suppressed by the Notch1 signaling pathway inhibitor DAPT. $\mathbf{a}, \mathbf{b}$ DAPT significantly decreased the expression of NICD in rats after RIPC + MCAO/R. ${ }^{* *} P<0.01$ vs. DMSO group. c Protein bands of NICD, Hes1, p-IKK a/ $\beta$, p-NF-KB p65, BCl-2, Bax, and $\beta$-actin from Western blot analysis. d, e RIPC significantly upregulated the expression of proteins related to the Notch1 and NF-KB signaling pathways. The Notch1 signaling pathway inhibitor DAPT reduced the activity of the NF-KB signaling pathway. Data are presented as the means \pm SEM; ${ }^{*} P<0.05,{ }^{*} P<0.01,{ }^{* *} P<0.001$ Vs. the RIPC + MCAO/R group, ${ }^{\#} P<0.05,{ }^{\# \#} P<0.01$ vs. the RIPC + MCAO/R + DMSO group 
cerebral ischemia-reperfusion injury [30-32]. However, the underlying mechanisms of RIPC-mediated neuroprotection are not fully understood [33, 34]. The present study demonstrates that RIPC significantly improved the outcome of rats subjected to $\mathrm{MCAO} / \mathrm{R}$ and that the neuroprotective effect of RIPC is related to activation of the Notch1 and NF- $\mathrm{kB}$ signaling pathways. In this study, we found that RIPC significantly reduced brain infarct volume and hippocampal neuronal apoptosis while improving neurological deficit scores in rats after $\mathrm{MCAO} / \mathrm{R}$, but the neuroprotective effect was attenuated by blocking the Notch1 pathway in vitro and in vivo. Furthermore, we found that the activity of the NF- $\mathrm{kB}$ pathway was affected by the Notch1 pathway during RIPC, exhibiting a synergistic change. These findings imply that the Notch1 signaling pathway is essential in the neuroprotective effects of RIPC, which may be achieved by modulating the activity of the NF- $\mathrm{kB}$ signaling pathway.

Limb RIPC is an attractive potential therapeutic strategy against ischemic stroke. RIPC-induced cerebral ischemic tolerance is achieved by intermittent, repeated, and sublethal episodes of ischemia and reperfusion in a limb, distant from the brain [33]. It has been reported that ischemic preconditioning-mediated ischemic tolerance is achieved in two different time windows: early or rapid preconditioning and delayed or classical preconditioning $[35,36]$. The delayed tolerance is achieved due to genetic alterations and protein synthesis and is the more significant of the two phases because of its longer duration [37]. The time interval between preconditioning and the subsequent insult is critical [38]. It has been reported that when the interval between ischemic preconditioning and subsequent potentially lethal cerebral ischemia is less than $3 \mathrm{~h}$. IPC has no protective effect but aggravates neuronal injury. However, when the interval is extended to $12-48 \mathrm{~h}$, ischemic tolerance prevails in the brain $[39,40]$. In previous studies, RIPC has been induced by 4 cycles of 5 min of left hind limb ischemia followed by 5 min of reperfusion for 1 day [41, 42]. It has been reported that repeated limb remote ischemic postconditioning provides cardioprotection against myocardial infarction more effectively than a single episode of limb preconditioning [43]. In our study, to durable, robust neuroprotection, we initiated 3-day RIPC before $\mathrm{MCAO} / \mathrm{R}$, with each day's procedure including 4 cycles of $5 \mathrm{~min}$ of ischemia followed by $5 \mathrm{~min}$ of reperfusion in the left hindlimb. The results showed that ischemic tolerance induced by RIPC effectively alleviated ischemiareperfusion injury in the rats after MCAO/R (Figs. 1, 6, and 7). OGD/R as a classical in vitro model for ischemia-reperfusion injury has been widely used in ischemic stroke studies $[24,44]$. The results from our in vitro study show that OGD preconditioning provides potent neuroprotection in hippocampal neurons exposed to
OGD/R by improving neuronal cell proliferation activity and antiapoptotic effects (Fig. 3e, f). This is consistent with previous observations $[26,45]$.

The underlying mechanisms of RIPC-mediated cerebral ischemic tolerance are intricate, multifactorial, and currently not well understood, although many preclinical studies and human clinical trials have been carried out. It has been reported that humoral and neurogenic pathways are involved in triggering intracellular signal pathways for neuroprotection [46-48]. The signaling pathway responsible for RIPC in the brain during ischemic injury is unclear. The involvement of multiple mediators suggests that more than one pathway is involved, which may act sequentially or in parallel for an additive effect [36]. Activation of Notch signal has been reported to play an important cardioprotective role following cardiac ischemic injury [49]. Notch signaling activation contributes to cardioprotection provided by ischemic preconditioning [9]. It was demonstrated that pretreatment with sevoflurane and isoflurane could reduce neuronal cell apoptosis and promote proliferation of neural stem cells during ischemia-reperfusion injury by activating the Notch signaling pathway. The neuroprotective effects of pretreatment were abrogated by blockade of the Notch signaling pathway, suggesting the critical role of Notch in the induction of cerebral ischemic tolerance [5, 8]. A recent study suggests that RIPC promotes arteriogenesis in the ischemic rat brain via increasing Notch signaling activity after ischemic stroke [10]. In our previous study, we also found that the neuroprotective effects of cerebral ischemic preconditioning (CIPC) in a rat MCAO/R model are mediated by the preactivation of the Notch1 signaling pathway [50]. In this study, we found that RIPC significantly increased the expression of NICD and Hes1 in the ischemic penumbra of the rats after MCAO/R (Fig. 2a, b; Fig. 8c, d), suggesting a stimulating effect of RIPC on Notch1 activity of the rats subjected to ischemia/reperfusion. We also found that Notch1 signaling in hippocampal neurons is activated by OGD preconditioning in the OGD/R model in vitro (Fig. 5b, c). In this study, we have shown that, 3 consecutive days of RIPC remarkably reduces ischemic infarct volume and hippocampal neuronal apoptosis in rats subjected to $\mathrm{MCAO} / \mathrm{R}$, but the neuroprotective effect of RIPC was attenuated by Notch1-RNAi in vitro and DAPT in vivo. Our results indicate that the Notch1 signaling pathway is essential for the formation of RIPC-mediated neuroprotective effects. Previous investigators suggested that Notch signaling might contribute to brain damage and functional outcome by activating microglial cells and stimulating the infiltration of proinflammatory leukocytes in ischemic stroke [4]. In our study, we found that when the Notch1 pathway was directly activated by lethal MCAO/R or OGD/R injury, it might play a damaging role, and blocking Notch1 signaling with DAPT or Notch1-RNAi could ameliorate the injury (Fig. 4 and Fig. 5a). The different observations may be 
related to the manner and the time point in which Notch signaling is activated, as well as its dynamically changing roles in different pathophysiological stages $[8,10,50]$. It was reported that cerebral ischemia and hypoxia could activate the Notch1 signaling pathway and four prominent interacting pathways (NF- $\mathrm{KB}, \mathrm{p} 53, \mathrm{HIF}-1 \alpha$ and Pin 1 ) that converge on a conserved DNA-associated nuclear multiprotein complex, which controls the expression of genes that could determine the fate of neurons. When neurons experience a sublethal ischemic stimulation (preconditioning), the nuclear multi-protein complex upregulates adaptive stress response genes encoding proteins that promote neuronal survival, but when ischemia is a lethal stimulation, the nuclear multi-protein complex induces genes encoding proteins that trigger and execute a neuronal death program [51]. In our study, we observed that when the Notch1 signaling was pre-activated by RIPC, it upregulated the expression of downstream protective genes by modulating the NF-kB pathway, resulting in neuroprotective effects against cerebral I/R injury. Previous studies have suggested that activation of NF- $\mathrm{kB}$ is essential in the induction of gene expression related to the neuroprotection mediated by ischemic preconditioning [52]. The activation of NF- $\mathrm{KB}$ in hippocampal neurons by ischemic preconditioning is a key event in brain ischemic tolerance [12]. In addition, it has been suggested that the activation of NF- $\mathrm{kB}$ in pyramidal neurons of the hippocampal CA1 region is an important axis of the IPC-mediated neuroprotective mechanism [11]. In the pathophysiological process of ischemia-reperfusion injury, the activation of NF- $\mathrm{KB}$ in different cell types determines its neuronal pro-death or prosurvival effects: NF- $\mathrm{KB}$ activation in neurons promotes their survival and plasticity, whereas NF- $\mathrm{kB}$ activation in glial cells enhances neuronal death $[11,53,54]$. In this study, we found that RIPC could upregulate the expression of p-IKK $\alpha / \beta$ and p-NF- $\mathrm{kB}$ p65 while activating the Notch1 signaling pathway, suggesting that RIPC activates the NF- $\mathrm{kB}$ pathway in cerebral ischemia-reperfusion injury. However, we also found that the activity of the NF-KB pathway was inhibited by the Notch1 inhibitors DAPT and Notch1-RNAi, suggesting that the NF-kB pathway is a downstream target of the Notch1 signaling pathway in RIPC. The mechanisms may be associated with reciprocal transcriptional regulation and physical interaction between Notch1 and NF- $\mathrm{KB}$ components, as well as the binding of Notch1 to components of the IKK complex $[13,55]$. It is believed that NF-kB plays a critical role in the induction of neuroprotective antiapoptotic gene products, such as MnSOD and $\mathrm{Bcl}-2$, which are known to contribute to ischemic tolerance [12]. In our study, we found that pre-activation of the NF- $\kappa B$ pathway in neuronal cells upregulated the expression of the downstream antiapoptotic gene Bcl-2, and reduced the expression of the proapoptotic gene Bax, producing neuroprotective effects (Fig. 5b, d; Fig. 8c, e). Unbalance in the expression of proapoptotic and antiapoptotic proteins may be related to the translocation of different subunits of the NF-kB pathway into the nucleus to activate different target genes [56]. Bcl-2 and Bax regulate the release of cytochrome $\mathrm{C}$ from the mitochondria via alteration of mitochondrial membrane potential and permeability, thereby regulating activation of caspases and the intrinsic mitochondrial apoptotic pathway. The proapoptotic activities of Bax are counteracted by Bcl-2 via retrotranslocating $B a x$ from the mitochondria back into the cytosol $[3,57,58]$.

Based on our in vitro and in vivo experiments, we can conclude that RIPC-mediated cerebral ischemic tolerance can be achieved by pre-activating the Notch 1 pathway in neurons, thereby upregulating the activity of $\mathrm{p}-\mathrm{IKK} \alpha / \beta$ and activating the NF- $\mathrm{KB}$ pathway in neuronal cells, resulting in changes in the expression of the apoptosis-related downstream genes Bcl-2 and Bax.

\section{Conclusions}

In summary, this study demonstrated that the neuroprotective effect of RIPC on cerebral I/R injury was associated with activation of the Notch1 and NF- $\mathrm{kB}$ pathways in neurons. The NF- $\mathrm{BB}$ pathway is a downstream target of the Notch1 signaling pathway in the protective effect of RIPC against focal cerebral I/R injury. Further studies are needed to clarify the exact mechanism of the interaction between the Notch1 and NF- $\mathrm{kB}$ pathways in RIPC-mediated neuroprotection. Since studies have now begun to translate RIPC to the clinic in several randomized trials with exciting outcomes, our results may provide some theoretical support for this clinical transformation.

\section{Abbreviations}

CCK-8: Cell counting kit-8; DMSO: Dimethyl sulfoxide; FACS: Fluorescenceactivated cell sorting; I/R: Ischemia-reperfusion; IKK: IKB kinase; IPC: Ischemic preconditioning; MCAO/R: Middle cerebral artery occlusion and reperfusion; OGD: Oxygen-glucose deprivation; OGD/R: Oxygen-glucose deprivation and reoxygenation; RIPC: Remote ischemic preconditioning; TTC: 2,3,5-Triphenyltetrazolium chloride solution

\section{Acknowledgements}

The authors would like to thank professor Zhihua Huang from the Provincial Key Laboratory of Cerebrovascular Diseases of Gannan Medical University for their technical assistance.

\section{Authors' contributions \\ WL designed the study, performed all experiments, analyzed the data, generated the figures, and wrote the manuscript. CL provided advice in the design of the study and in interpreting the data and revising the manuscript $L C, L Y, P G, P L, W W$, and $X Z$ conducted parts of the animal surgery and performed the experiments. All authors have read and approved the final version of the manuscript.}

\section{Funding}

This work was supported by the Science and Technology Research Project Fund of the Jiangxi Provincial Ministry of Education (No. GJJ160967).

Availability of data and materials

All data supporting the conclusions of this manuscript are provided in the text and figures. 


\section{Ethics approval and consent to participate}

All experimental procedures were approved by the Experimental Animal Ethics Committee of Southern Medical University and carried out in accordance with the National Institutes of Health Guide for the Care and Use of Laboratory Animals.

\section{Consent for publication}

Not applicable.

\section{Competing interests}

The authors declare that they have no competing interests.

\section{Author details}

'Nanfang Hospital, Southern Medical University, Guangzhou 510515, China. ${ }^{2}$ The First Affiliated Hospital of Gannan Medical University, Ganzhou 341000, China. ${ }^{3}$ Department of Anesthesia, Guangdong Provincial Hospital of Chinese Medicine, Guangzhou 510120, China

Received: 26 October 2018 Accepted: 29 August 2019

Published online: 16 September 2019

\section{References}

1. Stenzel-Poore MP, Stevens SL, Xiong Z, Lessov NS, Harrington CA, Mori M, Meller R, Rosenzweig HL, Tobar E, Shaw TE, et al. Effect of ischaemic preconditioning on genomic response to cerebral ischaemia: similarity to neuroprotective strategies in hibernation and hypoxia-tolerant states. Lancet. 2003;362:1028-37.

2. Schaller B, Graf $\mathrm{R}$, Jacobs $\mathrm{AH}$. Ischaemic tolerance: a window to endogenous neuroprotection? Lancet. 2003;362:1007-8.

3. Li S, Hafeez A, Noorulla F, Geng X, Shao G, Ren C, Lu G, Zhao H, Ding Y, Ji X Preconditioning in neuroprotection: from hypoxia to ischemia. Prog Neurobiol. 2017;157:79-91.

4. Arumugam TV, Chan SL, Jo DG, Yilmaz G, Tang SC, Cheng A, Gleichmann M, Okun E, Dixit VD, Chigurupati S, et al. Gamma secretase-mediated Notch signaling worsens brain damage and functional outcome in ischemic stroke. Nat Med. 2006:12:621-3.

5. Yang Q, Yan W, Li X, Hou L, Dong H, Wang Q, Dong H, Wang S, Zhang X, Xiong L. Activation of canonical notch signaling pathway is involved in the ischemic tolerance induced by sevoflurane preconditioning in mice. Anesthesiology. 2012;117:996-1005.

6. Ghai K, Zelinka C, Fischer AJ. Notch signaling influences neuroprotective and proliferative properties of mature Muller glia. J Neurosci. 2010;30:3101-12.

7. Guo YJ, Zhang ZJ, Wang SH, Sui YX, Sun Y. Notch1 signaling, hippocampal neurogenesis and behavioral responses to chronic unpredicted mild stress in adult ischemic rats. Prog Neuro-Psychopharmacol Biol Psychiatry. 2009;33:688-94.

8. Zhang HP, Sun $Y Y$, Chen XM, Yuan LB, Su BX, Ma R, Zhao RN, Dong HL, Xiong $\mathrm{L}$. The neuroprotective effects of isoflurane preconditioning in a murine transient global cerebral ischemia-reperfusion model: the role of the Notch signaling pathway. NeuroMolecular Med. 2014;16:191-204.

9. Zhou XL, Wan L, Xu QR, Zhao Y, Liu JC. Notch signaling activation contributes to cardioprotection provided by ischemic preconditioning and postconditioning. J Transl Med. 2013;11:251.

10. Ren C, Li S, Wang B, Han R, Li N, Gao J, Li X, Jin K, Ji X. Limb remote ischemic conditioning increases Notch signaling activity and promotes arteriogenesis in the ischemic rat brain. Behav Brain Res. 2018;340:87-93.

11. Lee JC, Tae HJ, Kim H, Cho JH, Lee TK, Park JH, Ahn JH, Choi SY, Bai HC, Shin BN, et al. Roles of HIF-1alpha, VEGF, and NF-kappaB in ischemic preconditioningmediated neuroprotection of hippocampal CA1 pyramidal neurons against a subsequent transient cerebral ischemia. Mol Neurobiol. 2017;54:6984-98.

12. Blondeau N, Widmann C, Lazdunski M, Heurteaux C. Activation of the nuclear factor-kappaB is a key event in brain tolerance. J Neurosci. 2001;21:4668-77.

13. Schwarzer $R$, Dorken $B$, Jundt $F$. Notch is an essential upstream regulator of NF-kappaB and is relevant for survival of Hodgkin and Reed-Sternberg cells. Leukemia. 2012;26:806-13.

14. Yao L, Kan EM, Kaur C, Dheen ST, Hao A, Lu J, Ling EA. Notch-1 signaling regulates microglia activation via NF-kappaB pathway after hypoxic exposure in vivo and in vitro. PLoS One. 2013;8:e78439.

15. Bash J, Zong WX, Banga S, Rivera A, Ballard DW, Ron Y, Gelinas C. Rel/NF-kappaB can trigger the Notch signaling pathway by inducing the expression of Jagged1, a ligand for Notch receptors. EMBO J. 1999;18:2803-11.
16. Ang HL, Tergaonkar V. Notch and NFkappaB signaling pathways: do they collaborate in normal vertebrate brain development and function? Bioessays. 2007;29:1039-47.

17. Wang Y, Chan SL, Miele L, Yao PJ, Mackes J, Ingram DK, Mattson MP, Furukawa K. Involvement of Notch signaling in hippocampal synaptic plasticity. Proc Natl Acad Sci U S A. 2004;101:9458-62.

18. Wang Z, Zhang Y, Li Y, Banerjee S, Liao J, Sarkar FH. Down-regulation of Notch-1 contributes to cell growth inhibition and apoptosis in pancreatic cancer cells. Mol Cancer Ther. 2006:5:483-93.

19. Longa EZ, Weinstein PR, Carlson S, Cummins R. Reversible middle cerebral artery occlusion without craniectomy in rats. Stroke. 1989;20:84-91.

20. Nasoohi S, Hemmati A, Moradi F, Ahmadiani A. The $\gamma$-secretase blocker DAPT impairs recovery from lipopolysaccharide-induced inflammation in rat brain. Neuroscience. 2012;210:99-109.

21. Zhang GS, Tian Y, Huang JY, Tao RR, Liao MH, Lu YM, Ye WF, Wang R, Fukunaga K, Lou YJ, Han F. The gamma-secretase blocker DAPT reduces the permeability of the blood-brain barrier by decreasing the ubiquitination and degradation of occludin during permanent brain ischemia. CNS Neurosci Ther. 2013:19:53-60.

22. Garcia JH, Wagner S, Liu K-F, Hu X-J. Neurological deficit and extent of neuronal necrosis attributable to middle cerebral artery occlusion in rats: statistical validation. Stroke. 1995;26:627-35.

23. Yang $X$, Wu Q, Zhang L, Feng L. Inhibition of histone deacetylase 3 (HDAC3) mediates ischemic preconditioning and protects cortical neurons against ischemia in rats. Front Mol Neurosci. 2016;9:131

24. Jiang M, Li J, Peng Q, Liu Y, Liu W, Luo C, Peng J, Li J, Yung KK, Mo Z. Neuroprotective effects of bilobalide on cerebral ischemia and reperfusion injury are associated with inhibition of pro-inflammatory mediator production and down-regulation of JNK1/2 and p38 MAPK activation. J Neuroinflammation. 2014;11:167.

25. Seibenhener ML, Wooten MW. Isolation and culture of hippocampal neurons from prenatal mice. J Vis Exp. 2012;65:1-6.

26. Scorziello A, Santillo M, Adornetto A, Dell'Aversano C, Sirabella R, Damiano S, Canzoniero LM, Renzo GF, Annunziato L. NO-induced neuroprotection in ischemic preconditioning stimulates mitochondrial Mn-SOD activity and expression via Ras/ERK1/2 pathway. J Neurochem. 2007;103:1472-80.

27. Grabb MC, Choi DW. Ischemic tolerance in murine cortical cell culture: critical role for NMDA receptors. J Neurosci. 1999:19:1657-62.

28. Young D, Lawlor PA, Leone P, Dragunow M, During MJ. Environmental enrichment inhibits spontaneous apoptosis, prevents seizures and is neuroprotective. Nat Med. 1999:5:448-53.

29. Ashwal S, Tone B, Tian HR, Cole DJ, Pearce WJ. Core and penumbral nitric oxide synthase activity during cerebral ischemia and reperfusion. Stroke. 1998;29:1037-47.

30. England TJ, Hedstrom A, O'Sullivan S, Donnelly R, Barrett DA, Sarmad S, Sprigg N, Bath PM. RECAST (remote ischemic conditioning after stroke trial): a pilot randomized placebo controlled phase II trial in acute ischemic stroke. Stroke. 2017:48:1412-5.

31. Meng R, Asmaro K, Meng L, Liu Y, Ma C, Xi C, Li G, Ren C, Luo Y, Ling F, et al. Upper limb ischemic preconditioning prevents recurrent stroke in intracranial arterial stenosis. Neurology. 2012;79:1853-61.

32. Hougaard KD, Hjort N, Zeidler D, Sorensen L, Norgaard A, Hansen TM, von Weitzel-Mudersbach P, Simonsen CZ, Damgaard D, Gottrup H, et al. Remote ischemic perconditioning as an adjunct therapy to thrombolysis in patients with acute ischemic stroke: a randomized trial. Stroke. 2014;45:159-67.

33. Moskowitz MA, Waeber C. Remote ischemic preconditioning: making the brain more tolerant, safely and inexpensively. Circulation. 2011;123:709-11.

34. Koch S, Gonzalez N. Preconditioning the human brain: proving the principle in subarachnoid hemorrhage. Stroke. 2013;44:1748-53.

35. Gidday JM. Cerebral preconditioning and ischaemic tolerance. Nat Rev Neurosci. 2006;7:437-48

36. Kanoria S, Jalan R, Seifalian AM, Williams R, Davidson BR. Protocols and mechanisms for remote ischemic preconditioning: a novel method for reducing ischemia reperfusion injury. Transplantation. 2007:84:445-58.

37. Thushara VN, Sangwan A, Sharma B, Majid A, Rajanikant GK. Cerebral ischemic preconditioning: the road so far. Mol Neurobiol. 2016:53:2579-93.

38. Hess DC, Blauenfeldt RA, Andersen G, Hougaard KD, Hoda MN, Ding Y, Ji X. Remote ischaemic conditioning-a new paradigm of self-protection in the brain. Nat Rev Neurol. 2015;11:698-710.

39. Davis DP. Patel PM. Ischemic preconditioning in the brain Curr Opin Anaesthesiol. 2003;16:447-52. 
40. Hanyu S, Ito U, Hakamata Y, Yoshida M. Repeated unilateral carotid occlusion in Mongolian gerbils: quantitative analysis of cortical neuronal loss. Acta Neuropathol. 1993;86:16-20.

41. Jensen HA, Loukogeorgakis S, Yannopoulos F, Rimpilainen E, Petzold A, Tuominen H, Lepola P, Macallister RJ, Deanfield JE, Makela T, et al. Remote ischemic preconditioning protects the brain against injury after hypothermic circulatory arrest. Circulation. 2011;123:714-21.

42. Hahn CD, Manlhiot C, Schmidt MR, Nielsen TT, Redington AN. Remote ischemic per-conditioning: a novel therapy for acute stroke? Stroke. 2011;42:2960-2.

43. Wei M, Xin P, Li S, Tao J, Li Y, Li J, Liu M, Li J, Zhu W, Redington AN. Repeated remote ischemic postconditioning protects against adverse left ventricular remodeling and improves survival in a rat model of myocardial infarction. Circ Res. 2011;108:1220-5.

44. Papadakis M, Hadley G, Xilouri M, Hoyte LC, Nagel S, McMenamin MM, Tsaknakis G, Watt SM, Drakesmith CW, Chen R, et al. Tsc1 (hamartin) confers neuroprotection against ischemia by inducing autophagy. Nat Med. 2013;19:351-7.

45. Tauskela JS, Brunette E, Monette R, Comas T, Morley P. Preconditioning of cortical neurons by oxygen-glucose deprivation: tolerance induction through abbreviated neurotoxic signaling. Am J Physiol Cell Physiol. 2003;285:C899-911.

46. Weber C. Far from the heart: receptor cross-talk in remote conditioning. Nat Med. 2010;16:760-2.

47. Hess DC, Hoda MN, Bhatia K. Remote limb perconditioning [corrected] and postconditioning: will it translate into a promising treatment for acute stroke? Stroke. 2013;44:1191-7.

48. Lim SY, Yellon DM, Hausenloy DJ. The neural and humoral pathways in remote limb ischemic preconditioning. Basic Res Cardiol. 2010;105:651-5.

49. Gude NA, Emmanuel G, Wu W, Cottage $C$, Fischer K, Quijada P, Muraski JA, Alvarez R, Rubio M, Schaefer E, Sussman MA. Activation of Notch-mediated protective signaling in the myocardium. Circ Res. 2008;102:1025-35.

50. Chen L, Huang K, Wang R, Jiang Q, Wu Z, Liang W, Guo R, Wang L. Neuroprotective effects of cerebral ischemic preconditioning in a rat middle cerebral artery occlusion model: the role of the Notch signaling pathway. Biomed Res Int. 2018:2018:8168720.

51. Arumugam TV, Baik SH, Balaganapathy P, Sobey CG, Mattson MP, Jo DG. Notch signaling and neuronal death in stroke. Prog Neurobiol. 2018;165-167:103-16.

52. Kim EJ, Raval AP, Hirsch N, Perez-Pinzon MA. Ischemic preconditioning mediates cyclooxygenase-2 expression via nuclear factor-kappa B activation in mixed cortical neuronal cultures. Transl Stroke Res. 2010;1:40-7.

53. Jiang W, Zhang S, Fu F, Zhu H, Hou J. Inhibition of nuclear factor-kappaB by 6-O-acetyl shanzhiside methyl ester protects brain against injury in a rat model of ischemia and reperfusion. J Neuroinflammation. 2010;7:55.

54. Chang YC, Huang CC. Perinatal brain injury and regulation of transcription. Curr Opin Neurol. 2006;19:141-7.

55. Osipo C, Golde TE, Osborne BA, Miele LA. Off the beaten pathway: the complex cross talk between Notch and NF-kappaB. Lab Investig. 2008;88:11-7.

56. Lanzillotta A, Porrini V, Bellucci A, Benarese M, Branca C, Parrella E, Spano PF, Pizzi M. NF-kappaB in innate neuroprotection and age-related neurodegenerative diseases. Front Neurol. 2015;6:98.

57. Santos LC, Vogel R, Chipuk JE, Birtwistle MR, Stolovitzky G, Meyer P. Mitochondrial origins of fractional control in regulated cell death. Nat Commun. 2019;10:1313.

58. Edlich F. BCL-2 proteins and apoptosis: recent insights and unknowns. Biochem Biophys Res Commun. 2018;500:26-34

\section{Publisher's Note}

Springer Nature remains neutral with regard to jurisdictional claims in published maps and institutional affiliations.

Ready to submit your research? Choose BMC and benefit from:

- fast, convenient online submission

- thorough peer review by experienced researchers in your field

- rapid publication on acceptance

- support for research data, including large and complex data types

- gold Open Access which fosters wider collaboration and increased citations

- maximum visibility for your research: over $100 \mathrm{M}$ website views per year

At BMC, research is always in progress.

Learn more biomedcentral.com/submissions 